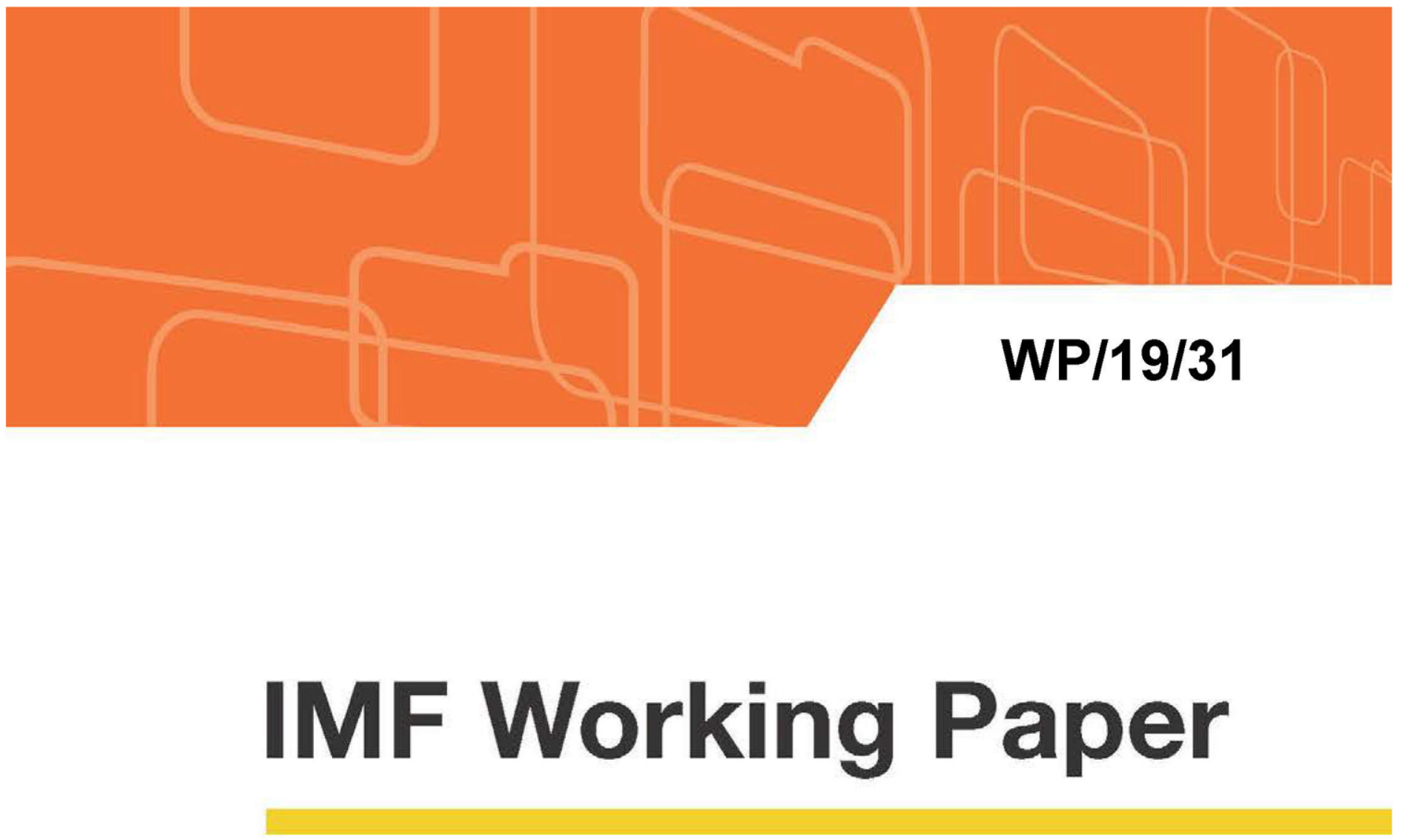

\title{
Demographics and the Natural Rate of Interest in Japan
}

\author{
by Fei Han
}

IMF Working Papers describe research in progress by the author(s) and are published to elicit comments and to encourage debate. The views expressed in IMF Working Papers are those of the author(s) and do not necessarily represent the views of the IMF, its Executive Board, or IMF management.

$$
\text { I N T E R N A T I O N A L M O N E T A R Y FU N D }
$$




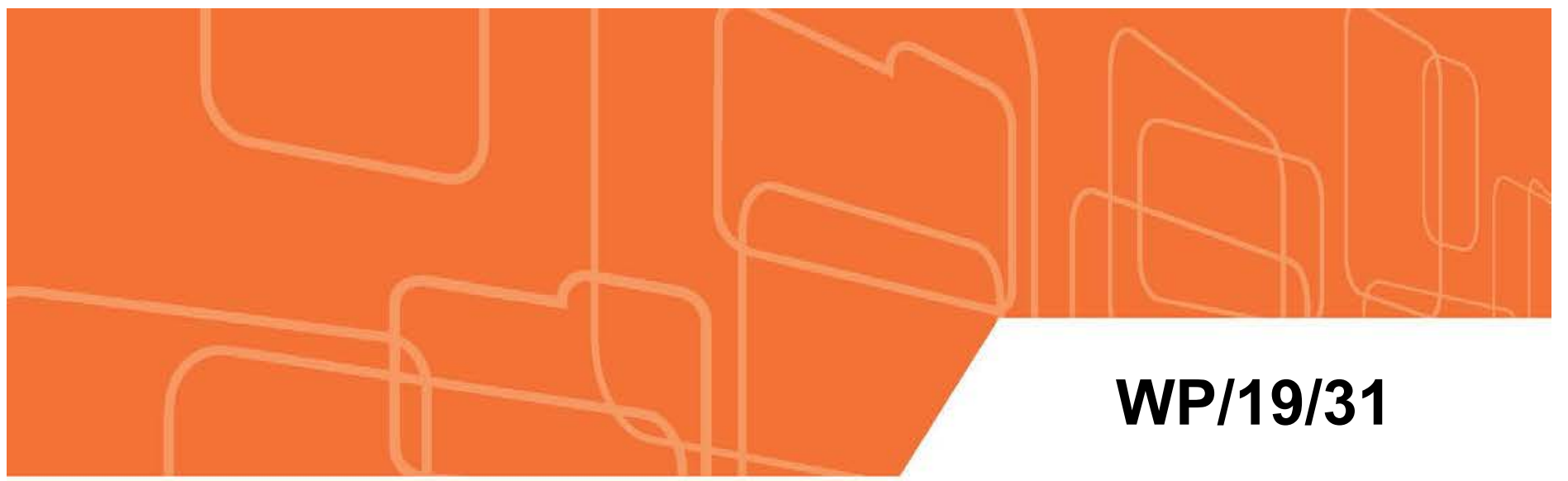

\section{IMF Working Paper}

\section{Demographics and the Natural Rate of Interest in Japan}

by Fei Han

IMF Working Papers describe research in progress by the author(s) and are published to elicit comments and to encourage debate. The views expressed in IMF Working Papers are those of the author(s) and do not necessarily represent the views of the IMF, its Executive Board, or IMF management. 


\title{
IMF Working Paper
}

Asia and Pacific Department and Monetary and Capital Markets Department

\section{Demographics and the Natural Rate of Interest in Japan}

Prepared by Fei Han ${ }^{1}$

Authorized for distribution by Paul Cashin and Ulric Eriksson von Allmen

February 2019

\section{IMF Working Papers describe research in progress by the author(s) and are published to elicit comments and to encourage debate. The views expressed in IMF Working Papers are those of the author(s) and do not necessarily represent the views of the IMF, its Executive Board, or IMF management.}

\begin{abstract}
Japan's aging and shrinking population could lower the natural rate of interest and, together with low inflation expectations, challenge the Bank of Japan's efforts to reflate the economy. This paper uses a semi-structural model to estimate the impact of demographics on the natural rate in Japan. We find that demographic change has a significantly negative impact on the natural rate by lowering trend potential growth. We also find that the negative impact has been increasing over time amid stronger demographic headwinds. These findings highlight the importance of boosting potential growth to offset the negative demographic impact and lift the natural rate in Japan.
\end{abstract}

JEL Classification Numbers: C11, C32, E43, E52

Keywords: Demographic change, natural rate of interest, monetary policy, Japan Author's E-Mail Address: fhan@imf.org

\footnotetext{
${ }^{1}$ The author would like to thank Stephanie Y. F. Ng and Anh V. Le for excellent research assistance. The author is also very grateful to Paul Cashin, Vassili Bazinas, Mariana Colacelli, Philipp Engler, Gee Hee Hong, Callum Jones, Mitsuru Katagiri, Signe Krogstrup, Kazuaki Miyachi, Masashi Saito, Todd Schneider, Jarkko Turunen, Niklas Westelius, Pawel Zabczyk (all IMF), Yoshihito Saito (IMF Alternative Executive Director), Nao Sudo (Bank of Japan) and other seminar participants at the Bank of Japan for their valuable suggestions and comments. All errors are my own.
} 
Contents

Page

Abstract 1

I. Introduction $\underline{3}$

II. Econometric Framework $\underline{8}$

III. Bayesian Estimation: Priors and Data $\underline{13}$

IV. Baseline Results $\underline{16}$

V. Robustness 21

VI. Conclusions and Policy Implications 26

References $\underline{28}$

\section{Figures}

1. Natural Rate of Interest $\underline{18}$

2. Determinants of the Natural Rate of Interest $\underline{20}$

3. Natural Rate of Interest with Alternative Priors $\underline{22}$

4. Natural Rate of Interest without $\mathrm{Z}$-Controls 23

5. Natural Rate of Interest without $\mathrm{z}$-Controls

25

6. Natural Rate of Interest Based on 10-Year Interest Rate

$\underline{26}$

\section{Tables}

1. Priors $\underline{15}$

2. Estimation Results: Posteriors 17

3. Alternative Priors of $\mathrm{c}$ and $\alpha \mathrm{r}$

$\underline{24}$




\section{INTRODUCTION}

Nominal interest rates in Japan have reached the zero lower bound (ZLB) but inflation remains subdued. Nominal short-term interest rate in Japan has fallen substantially and has been at the ZLB since the late 1990s. Similarly, nominal long-term interest rates have also fallen substantially since the global financial crisis (GFC), with the 10-year rate reaching the ZLB in early 2016 when the negative interest rate policy was introduced in Japan. However, core inflation has remained well below the Bank of Japan (BoJ)'s inflation target of two percent, and inflation expectations, despite a modest increase, are still anchored at close to zero. These developments call into the question how much monetary stimulus has been provided to the real economy.
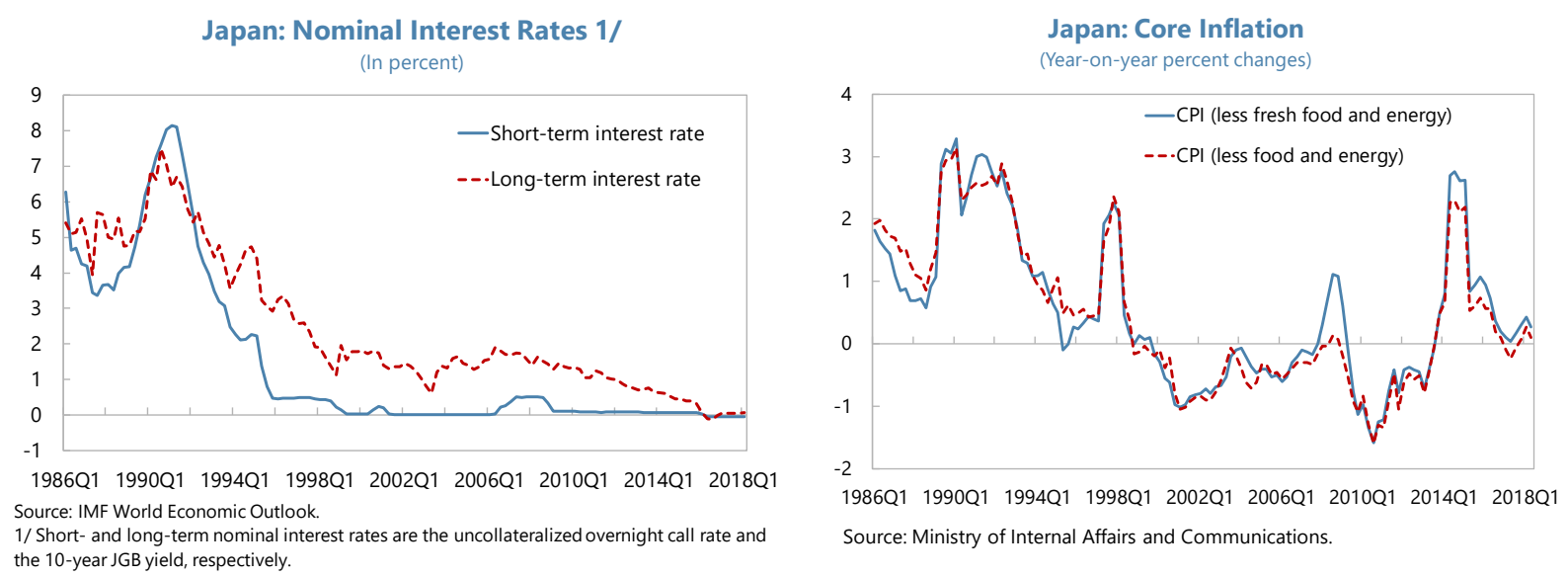

The extent of monetary stimulus depends on the interest rate gap-defined as the gap between the real interest rate and the natural rate of interest. The real interest rate (more precisely, the ex ante real interest rate) is calculated by subtracting expected inflation from the nominal interest rate. The natural rate of interest is defined as the real interest rate consistent with output equaling its potential level and constant inflation (Laubach and Williams, 2003). The natural rate of interest therefore provides a benchmark for measuring the stance of monetary policy. Policy is deemed to be expansionary (contractionary) if the real interest rate lies below (above) the natural rate. The basic mechanism of monetary easing-regardless of whether it is conducted through conventional or unconventional policy means - consists of driving the real interest rate below the natural rate of interest. It is also referred to as the "equilibrium" real interest rate. From a theoretical perspective, it can also be defined as the real interest rate which balances savings and investment under full employment. In other words, other things being equal, output falls below the level of full employment, lowering price levels, when the real interest rate exceeds the natural rate of interest (that is, when the real interest rate gap is positive), and output and prices increase if otherwise.

How large has the real interest rate gap been in Japan? As BoJ Governor Kuroda said in his speech at the University of Oxford in 2017, “... as nominal short-term interest rates faced the zero lower bound, it was difficult to lower real interest rates to levels well below the 
natural rate of interest and achieve sufficient monetary easing." Indeed, with nominal interest rate and inflation expectation in Japan constrained by the ZLB and deflationary mindset, respectively, the extent of monetary stimulus could be limited if the natural rate of interest is low, challenging the ability of monetary policy to reflate the economy.

There is considerable evidence that the natural rate of interest may have fallen to historically low levels in most major advanced economies. For example, Holston et al. (2017) document a sharp downward trend in equilibrium real rates in the United States, Canada, the Euro Area, and the United Kingdom. Broadly speaking, there are two main hypotheses used to explain the decline in the natural rate in leading economies: (i) the secular stagnation hypothesis (Summers, 2014); and (ii) the global savings glut hypothesis (Bernanke, 2005). Both hypotheses posit an excess of desired saving over desired capital investment at "normal" interest rates (Bernanke, 2017). However, the secular stagnation hypothesis attributes weakness in capital investment to fundamental factors such as demographic change, while the savings glut hypothesis attributes it to government policy decisions.

In the secular stagnation hypothesis, demographic change is an important factor in explaining the decline in the natural rate of interest through reducing potential growth. This hypothesis, advanced by Alvin Hansen in the 1930s and revived by Summers (2014), holds that the main driving forces of lower rates are a persistent downshift in trend economic growth and an associated decline in the returns to capital investment. According to this hypothesis, an aging and shrinking population could reduce the labor force, slow productivity growth, and increase the capital-to-labor ratio. As a result, both potential growth and the marginal return on domestic capital

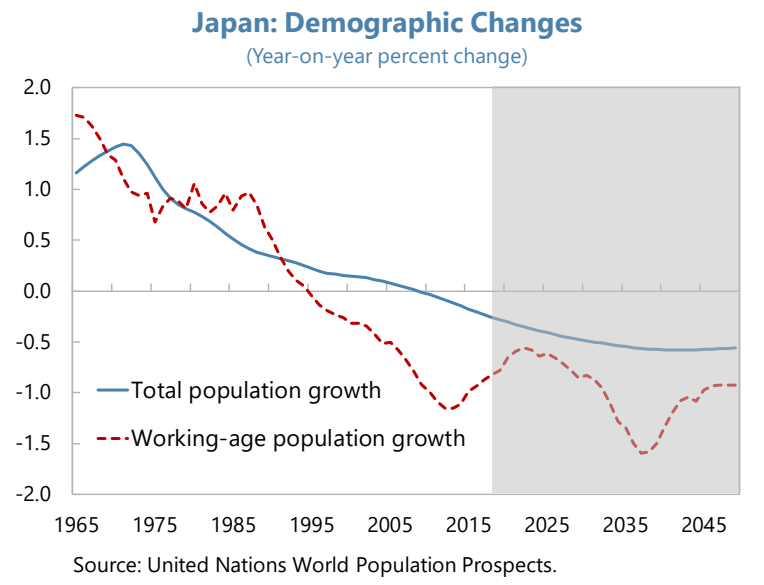
investments will decline. Potential growth is the key variable that links demographic changes with the natural rate of interest in this hypothesis. Since Japan has had - and will continue to have - significant demographic changes as working-age population growth declined since late 1980s, understanding the impact of demographic change on the natural rate of interest is especially important for Japan.

Demographic change may also affect the natural rate of interest in the global savings glut hypothesis. This alternative hypothesis proposed by Bernanke (2005) focuses on the global imbalances between high desired savings and low desired investment of some economies. This view emphasizes that some excess saving is the result of policy decisions, including, for example, the accumulation of large foreign exchange reserves by some countries. Having said that, demographic change could still affect excess global savings by 
changing investors' preference for safe assets, thereby putting downward pressure on the real equilibrium interest rate (Pescatori and Turunen, 2016). Moreover, using an open-economy OLG model, Coeurdacier et al. (2015) showed that the age-savings profiles in the U.S. and China, combined with growth differentials and household credit constraints, could explain the divergence in private savings rates and a sustained decline in the world interest rate, providing micro-foundations to the global savings glut hypothesis.

\section{In addition to the channels discussed in these two hypotheses, demographic change} in Japan can also affect the natural rate of interest through other channels. According to Carvalho et al. (2016), the increasing longevity in Japan may have put downward pressure on the real interest rate, as agents build up their savings in anticipation of a longer retirement period. Moreover, the declining population growth rate in Japan could have two counteracting effects. Although it could lower real interest rates

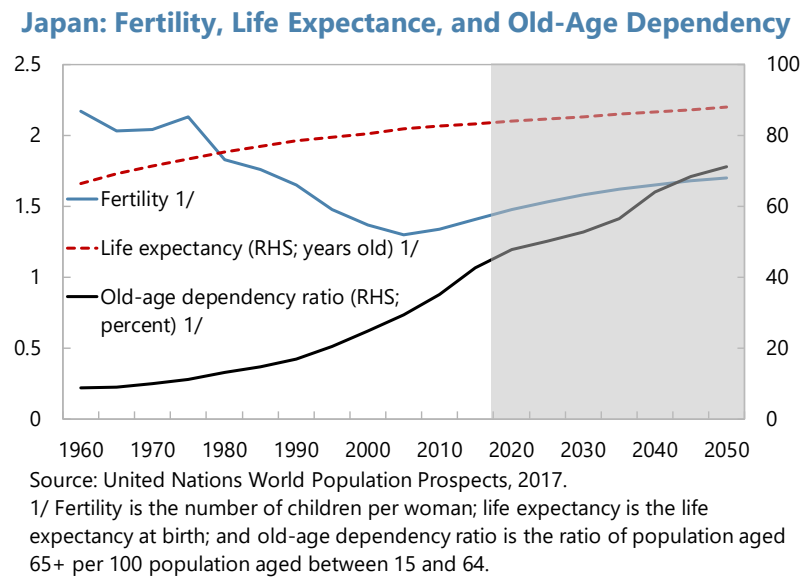
through reducing the marginal return on capital on the one hand, it also leads to a higher dependency ratio (the ratio of retirees to workers) on the other hand, which could reduce the aggregate savings rate (due to lower savings of retirees than workers) and push up real interest rates.

To uncover the impact of demographic change on the natural rate of interest, an estimation method of the natural rate is needed as it is not observable. Broadly speaking, there are two approaches to estimating the natural rate of interest-statistical and structural. The first approach estimates the natural rate of interest as the trend component of the actual real interest rate using statistical filters or more complicated statistical models, which only exploit the time series of the real interest rate alone. The second approach defines the natural rate as the "equilibrium" real interest rate that is consistent with a theoretical requirement of output equaling its potential level and stable inflation, using a structural economic model that exploits the structural relationships between the real interest rate and other macroeconomic variables. ${ }^{2}$ In this approach, both dynamic stochastic general equilibrium (DSGE) models (e.g., Barsky et al., 2014 and Curdia et al., 2015) and semi-structural models have been widely used by academia and central banks. While the natural rate is a stationary linear combination of transitory shocks to preferences and technology in the DSGE models, it is explicitly allowed to be affected by low-frequency nonstationary processes and hence be

\footnotetext{
${ }^{2}$ Lubik and Matthes (2015) used a Bayesian vector autoregression to estimate the natural rate of interest in the United States, which falls in this approach but does not explicitly exploit the economic structure.
} 
more persistent in the semi-structural models (Holston et al. 2017). ${ }^{3}$ This is because that the semi-structural models typically link the natural rate directly with the trend potential growth rate following the seminal paper by Laubach and Williams (2003) (hereafter, LW model). ${ }^{4}$

\begin{abstract}
Although demographic change is believed to be a key factor driving the natural rate of interest in the secular stagnation hypothesis, the literature provides only limited quantification of the impact. Many studies, for example, Ikeda and Saito (2014), have extended the DSGE model to analyze the effects of demographic change on the real interest rate. ${ }^{5}$ Also using the DSGE approach, Okazaki and Sudo (2018) first estimated the impact of potential drivers, including demographic factors, on Japan's natural rate of interest. In the other strand of research using semi-structural models, there have been studies that extended the LW model to estimate the impact of some other drivers (treated as exogenous variables) on the natural rate. For example, Pescatori and Turunen (2016) estimated the impact of excess global savings (following the global savings glut hypothesis), risk premium, and policy uncertainty on the natural rate of interest in the United States. By applying the LW model to the United States and some other advanced economies, Holston et al. (2017) found that global factors could play an important role in shaping trend growth and the natural rate of interest. However, to the best of our knowledge, there have not been studies that use the semi-structural approach (which allows the natural rate to be affected by nonstationary processes) to explicitly model the role of demographic factors in determining the natural rate.
\end{abstract}

This paper tries to address the following questions. How large is the gap between the natural rate and real interest rate in Japan? How much impact has demographic change had on the natural rate of interest in Japan? Addressing these questions could help understand how much monetary stimulus has been provided to the economy and provide insights on how demographic changes may affect Japan's natural rate and monetary policy going forward. Since demographic change could affect the natural rate through many channels as discussed before, this paper focuses on the channel considered in the secular stagnation hypothesis.

\title{
This paper contributes to the literature by extending the current semi-structural models to explicitly model the impact of demographic change using the production
} function approach. Based on Pescatori and Turunen (2016), this paper further extends the

\footnotetext{
${ }^{3}$ In other words, the semi-structural models relax the assumptions about the steady state that most DSGE models use to derive log-linear approximations of the dynamics of inflation and the output gap (Holston et al. 2017).

${ }^{4}$ See, for example, Fries et al. (2016), Pescatori and Turunen (2016), Hakkio and Smith (2017), Holston et al. (2017), IMF (2017), and Lewis and Vazquez-Grande (2017) for estimates based on the semi-structural model of Laubach and Williams (2003).

${ }^{5}$ OLG models have also been used to estimate the effects of demographic change on the real interest rates in the U.S. For example, by using an OLG model, Gagnon et al. (2016) showed that the family composition, life expectancy, and labor supply have had a significant impact on the natural rate of interest in the U.S. since 1980. Jones (2018) found that demographic changes have generated slow-moving trends in the real interest rate, employment, and productivity in the U.S.
} 
LW model to explicitly model the impact of demographic changes on the natural rate of interest and the transmission channels by using the production function decomposition (see, e.g., Kawamoto et al., 2017). In other words, the contribution of demographic changes to the natural rate of interest is treated as part of the entire contributions of the trend potential growth and estimated separately from the latter. ${ }^{6}$ We then follow Pescatori and Turunen (2016) and estimate the model for Japan using a Bayesian approach that allows us to incorporate prior information on the output gap and potential output based on the estimates and projections by the IMF's World Economic Outlook (WEO).

\section{We find that demographic change has had a significantly negative impact on the} natural rate of interest in Japan in recent years. Since the GFC, the decline in workingage population growth has contributed to about -0.3 percentage points on average to the estimated negative natural rate - which is about -0.7 percent during this period. More importantly, such a negative impact is found to be increasing gradually over time, from less than -0.2 percentage points in Q1 2010 to -0.4 percentage points in Q1 2018. We also find that Japan's natural rate has likely fallen into the negative territory since late 1990s, making it difficult for monetary policy to lower real interest rates below the natural rate of interest to provide monetary stimulus given low inflation expectations.

These findings are broadly in line with the existing literature. For example, Imakubo et al. (2015) and Fujiwara et al. (2016) found that the natural rate of interest in Japan has followed a downward trend since the 1990s, although their estimates of the natural rate were generally higher than those of this paper. More recently, by constructing a DSGE model with demographic factors and financial frictions, Okazaki and Sudo (2018) also found that demographic changes (working-age population to be more precise) have had a negative and increasing impact on the natural rate of interest in Japan since early 2000s, and the impact is of similar magnitude as what we find in this paper. Moreover, our findings are also in line with empirical literature (e.g., Aiyar et al., 2016 and Liu and Westelius, 2017) which found that demographic changes have had significant effects on potential growth through reducing labor inputs and the growth rate of total factor productivity (TFP) in many advanced economies, including Japan.

The rest of the paper is organized as follows. Section II develops the econometric model that integrates demographic factors into the semi-structural model for the natural rate of interest. Section III presents the Bayesian method used to estimate the model for Japan, including assumptions on the priors of parameters and data. Section IV presents the baseline results of the impact of demographic changes on the natural rate of interest in Japan and discusses the key drivers of the natural rate. Section V provides robustness checks of the baseline results. Section VI concludes the paper and discusses policy implications.

\footnotetext{
${ }^{6}$ Although some other channels discussed above (e.g., through longevity and a higher old-age dependency ratio) are not explicitly captured in the semi-structural model, we try to capture these channels through using the proxy of excess savings in Japan (i.e., current account surplus of Japan).
} 


\section{ECONOMEtric Framework}

\section{In this section, we extend the semi-structural models developed by Laubach and} Williams (2003) and Pescatori and Turunen (2016) to incorporate demographic factors. The LW model is a state-space model with a core system including an IS curve relating the output gap to interest rate gaps, a backward-looking Phillips curve relating core inflation to the output gap, and an equation that links the natural rate of interest to its determinants. The Pescatori and Turunen (2016) model extended the Laubach and Williams (2003) model by: i) introducing other exogenous variables that could affect the natural rate of interest in addition to trend potential output growth, ii) introducing measurement errors to the potential output, and iii) estimating the model with Bayesian methods rather than the Maximum Likelihood Estimation (MLE). To explicitly model the effects of demographics on the natural rate, we follow Kawamoto and others (2017) and decompose potential output into factors of production, i.e., labor input, capital input, and TFP which measures the efficiency with which the labor and capital inputs are used:

$$
Y_{t}^{*}=A_{t}^{*}\left(L_{t}^{*}\right)^{\alpha}\left(K_{t}^{*}\right)^{1-\alpha},
$$

where $Y_{t}^{*}$ is potential output, and $A_{t}^{*}, L_{t}^{*}, K_{t}^{*}$ are potential TFP, labor, and capital inputs, respectively. Taking the logarithm of both sides of equation (1) and the difference between them, we obtain:

$$
\Delta y_{t}^{*}=\Delta a_{t}^{*}+\alpha \Delta l_{t}^{*}+(1-\alpha) \Delta k_{t}^{*}
$$

where $\Delta a_{t}^{*}, \Delta l_{t}^{*}$, and $\Delta k_{t}^{*}$ are the first differences of the logarithms of $A_{t}^{*}, L_{t}^{*}$, and $K_{t}^{*}$, respectively.

The potential labor input can be decomposed into four factors: (i) working-age population; (ii) potential labor force participation rate; (iii) potential employment rate; and (iv) potential total working hours per worker. In particular, we can write labor input $L_{t}^{*}$ as

$$
L_{t}^{*}=F_{t} P_{t}^{*} E_{t}^{*} H_{t}^{*}
$$

where $F_{t}, P_{t}^{*}, E_{t}^{*}$, and $H_{t}^{*}$ are the four factors mentioned above, respectively. Notice that the working-age population does not vary in accordance with the business cycle. Following the United Nations' World Population Prospects, the working-age population is defined as those aged between 15 and 64 years old. ${ }^{7}$ Taking the logarithm of both sides of equation (3) and the difference between them, we obtain:

$$
\Delta l_{t}^{*}=\Delta f_{t}+\Delta p_{t}^{*}+\Delta e_{t}^{*}+\Delta h_{t}^{*}
$$

\footnotetext{
${ }^{7}$ An alternative definition of the working-age population (i.e., those aged between 15 and 69 years old) is also used to capture - to some extent - the effects of longevity. However, this does not qualitatively change the estimation results.
} 
where $\Delta f_{t}, \Delta p_{t}^{*}, \Delta e_{t}^{*}$, and $\Delta h_{t}^{*}$ are the first differences of the logarithms of the four factors for labor input, representing the growth rates of working-age population, potential labor force participation rate, potential employment rate, and potential total working hours per worker, respectively.

We assume that the growth rate of each potential factor of production can be decomposed into a trend process and a noise. Specifically, we assume:

$$
\begin{aligned}
& \Delta a_{t}^{*}=g_{t}^{a}+\varepsilon_{t}^{a}, \\
& \Delta k_{t}^{*}=g_{t}^{k}+\varepsilon_{t}^{k}, \\
& \Delta p_{t}^{*}=g_{t}^{p}+\varepsilon_{t}^{p}, \\
& \Delta e_{t}^{*}=g_{t}^{e}+\varepsilon_{t}^{e}, \\
& \Delta h_{t}^{*}=g_{t}^{h}+\varepsilon_{t}^{h},
\end{aligned}
$$

where the processes $g^{a}, g^{k}, g^{p}, g^{e}$, and $g^{h}$ can be interpreted as the trend potential growth rates of production factors (except the working-age population), and the noise processes, $\varepsilon^{a}$, $\varepsilon^{k}, \varepsilon^{p}, \varepsilon^{e}$, and $\varepsilon^{h}$, are i.i.d. innovations with standard deviations $\sigma_{a}, \sigma_{k}, \sigma_{p}, \sigma_{e}$, and $\sigma_{h}$, respectively. If we define

$$
g_{t}^{y} \equiv g_{t}^{a}+\alpha\left(g_{t}^{p}+g_{t}^{e}+g_{t}^{h}\right)+(1-\alpha) g_{t}^{k}
$$

and

$$
\varepsilon_{t}^{y} \equiv \varepsilon_{t}^{a}+\alpha\left(\varepsilon_{t}^{p}+\varepsilon_{t}^{e}+\varepsilon_{t}^{h}\right)+(1-\alpha) \varepsilon_{t}^{k}
$$

then equation (2) can be re-written as

$$
\Delta y_{t}^{*}=g_{t}^{y}+\alpha \Delta f_{t}+\varepsilon_{t}^{y},
$$

where $\varepsilon^{y}$ is an i.i.d. innovation. We can denote the standard deviation of $\varepsilon^{y}$ by $\sigma_{y}$. Equation (12) suggests that the working-age population growth $\Delta f_{t}$ could have a direct impact on the potential output growth $\Delta y_{t}^{*}$.

We assume that working-age population growth could also have an indirect impact on potential output growth through its effect on the trend potential growth rate of each factor of production. In particular, we assume that the trend potential growth rates $g$ follow a random walk with exogenous variables of contemporaneous and lagged working-age population growth. ${ }^{8}$

\footnotetext{
${ }^{8}$ The assumption that only one lag of the working-age population growth is included in the equations is based on the results from single-equation regressions of the first difference of trend potential growth (estimated by HP filter) against the lags of working-age population growth. Moreover, we also include the change in the old-age
} 


$$
\begin{aligned}
& g_{t}^{a}=g_{t-1}^{a}+\theta_{0}^{a} \Delta f_{t}+\theta_{1}^{a} \Delta f_{t-1}+\varepsilon_{t}^{g a}, \\
& g_{t}^{k}=g_{t-1}^{k}+\theta_{0}^{k} \Delta f_{t}+\theta_{1}^{k} \Delta f_{t-1}+\varepsilon_{t}^{g k}, \\
& g_{t}^{p}=g_{t-1}^{p}+\theta_{0}^{p} \Delta f_{t}+\theta_{1}^{p} \Delta f_{t-1}+\varepsilon_{t}^{g p}, \\
& g_{t}^{e}=g_{t-1}^{e}+\theta_{0}^{e} \Delta f_{t}+\theta_{1}^{e} \Delta f_{t-1}+\varepsilon_{t}^{g e}, \\
& g_{t}^{h}=g_{t-1}^{h}+\theta_{0}^{h} \Delta f_{t}+\theta_{1}^{h} \Delta f_{t-1}+\varepsilon_{t}^{g h},
\end{aligned}
$$

where the noise processes, $\varepsilon^{g a}, \varepsilon^{g k}, \varepsilon^{g p}, \varepsilon^{g e}$, and $\varepsilon^{g h}$, are i.i.d. innovations and are independent from the noise processes $\left\{\varepsilon^{a}, \varepsilon^{k}, \varepsilon^{p}, \varepsilon^{e}, \varepsilon^{h}\right\}$ in equations (5)-(9). With some simple algebra, we can derive an equation to characterize the dynamics of the process $g_{t}^{y}$ defined in equation (10):

$$
g_{t}^{y}=g_{t-1}^{y}+\theta_{0} \Delta f_{t}+\theta_{1} \Delta f_{t-1}+\varepsilon_{t}^{g},
$$

where $\theta_{i} \equiv \theta_{i}^{a}+\alpha\left(\theta_{i}^{p}+\theta_{i}^{e}+\theta_{i}^{h}\right)+(1-\alpha) \theta_{i}^{k}$ for $i=0,1$, and $\varepsilon_{t}^{g} \equiv \varepsilon_{t}^{g a}+$ $\alpha\left(\varepsilon_{t}^{g p}+\varepsilon_{t}^{g e}+\varepsilon_{t}^{g h}\right)+(1-\alpha) \varepsilon_{t}^{g k}$. Notice that $\varepsilon^{g}$ is an i.i.d. innovation, and is independent from the innovation $\varepsilon^{y}$ defined in equation (11). We denote the standard deviation of $\varepsilon^{g}$ by $\sigma_{g}$.

\section{This assumption of indirect effects of demographic change on potential output growth}

is line with previous findings in the literature. Many studies have found that demographic change could have significant effects on labor inputs and TFP growth. For example, using a panel on U.S. states, Mestas and others (2016) estimated the impact of the old-age dependency ratio on GDP per capita, and found that two-thirds of the impact was due to slower productivity growth across the entire age distribution and one-third was due to slower labor force growth. Similarly, in a cross-country panel study for European countries, Aiyar et al. (2016) found that workforce aging is associated with a reduction in TFP growth in Europe. Moreover, using a similar methodology but prefecture-level data on Japan, Liu and Westelius (2017) found that aging of the working-age population has had a significant negative impact on TFP in Japan. Feyrer (2007) found an inverted U-shaped relationship between the age distribution and TFP using a cross-country panel on OECD and low-income countries. Therefore, given that the working-age population growth is expected to have negative effects on labor inputs and TFP growth, we would expect $\theta_{0}$ to be positive. ${ }^{9}$

dependency ratio as another exogenous variable in the model, which does not cause any qualitative change in the estimation results.

${ }^{9}$ In theory, if the age-productivity profile is concave, then as a young workforce accumulates human capital and moves up the age-productivity profile (before reaching the peak), productivity growth should also be higher. Once the bulk of the working-age population reaches the peak of the productivity profile, overall productivity growth should fall. This implies that trend productivity growth can be related to the composition of the working-age population. We simply assume in this paper that the working-age population growth is a proxy for 
If we define

$$
g_{t} \equiv g_{t}^{y}+\alpha \Delta f_{t}
$$

then according to equation (18), we can characterize the dynamics of the process $g$ by

$$
g_{t}=g_{t-1}+\gamma_{0} \Delta f_{t}+\gamma_{1} \Delta f_{t-1}+\varepsilon_{t}^{g},
$$

where $\gamma_{0} \equiv \theta_{0}+\alpha$ and $\gamma_{1} \equiv \theta_{1}-\alpha$. Given that both $\theta_{0}$ and $\alpha$ are expected to be positive, we also expect $\gamma_{0}$ to be positive. At the same time, based on equation (19), we can re-write equation (12) as

$$
y_{t}^{*}=y_{t-1}^{*}+g_{t}+\varepsilon_{t}^{y},
$$

Thus, equations (20) and (21) together imply that the process $g$ can be interpreted as the trend growth rate of potential output. Moreover, the two equations also imply that the potential output growth $\Delta y_{t}^{*}$ can be decomposed into a trend potential output growth $(g)$, which is affected by contemporaneous and lagged working-age population growth, and a temporary noise $\left(\varepsilon^{y}\right)$. Compared to the original LW model and Pescatori and Turunen (2016), our extended model has two extra parameters, $\gamma_{0}$ and $\gamma_{1}$, which explicitly capture the impact of working-age population growth on the trend potential growth.

The rest of the core system follows Pescatori and Turunen (2016) - including an IS curve relating the output gap to interest rate gaps, a backward-looking Phillips curve relating core inflation to the output gap, and an equation that links the natural rate of interest to its determinants. Specifically, the IS curve and Phillips curve are characterized by the following equations:

$$
\begin{gathered}
x_{t}=\alpha_{1} x_{t-1}+\alpha_{2} x_{t-2}-\frac{\alpha_{r}}{2}\left(r_{t-1}-r_{t-1}^{*}+r_{t-2}-r_{t-2}^{*}\right)+\varepsilon_{t}^{x}, \\
\pi_{t}=\beta_{1} \pi_{t-1}+\frac{\beta_{2}}{3} \sum_{j=2}^{4} \pi_{t-j}+\frac{\left(1-\beta_{1}-\beta_{2}\right)}{4} \sum_{j=5}^{8} \pi_{t-j}+\beta_{x} x_{t-1}+\beta_{m} \pi_{t-1}^{m}+\varepsilon_{t}^{\pi}, \\
x_{t} \equiv 100 *\left(y_{t}-y_{t}^{*}\right),
\end{gathered}
$$

where $x_{t}$ is the output gap, $y_{t}$ is the actual log-output, $\pi_{t}$ is the core inflation, and $\pi_{t-1}^{m}$ is the lagged import relative price inflation. Although the output gap is not directly observable, the measure of output gap constructed by the IMF's WEO projections would likely provide valuable information for the estimation of the natural rate of interest. Therefore, we follow IMF (2017) and assume the following relation between the true output gap, $x_{t}$, and the WEO output gap, $x_{t}^{W E O}$ :

$$
x_{t}^{W E O}=x_{t}+\mu_{t}+\varepsilon_{t}^{W},
$$

the share of older workers, as the decline in working-age population is mostly driven by the exit of older workers due to population aging. 


$$
\mu_{t}=\rho \mu_{t}+\varepsilon_{t}^{\mu}
$$

where $\varepsilon^{w}$ and $\varepsilon^{\mu}$ are i.i.d. innovations with standard deviations $\sigma_{w}$ and $\sigma_{\mu}$, respectively. We also assume that they are independent from the other innovations mentioned above. The parameter $\rho$ and the standard deviations $\sigma_{w}$ and $\sigma_{\mu}$ determine the precision of the signal, $x_{t}^{W E O}$, relative to the noise $\left(\mu_{t}+\varepsilon_{t}^{W}\right)$.

Typical household intertemporal utility maximization yields the relationship between the real interest rate and growth:

$$
r=\frac{1}{\sigma} g^{c}+\vartheta
$$

where $r$ is the real interest rate, $\sigma$ is the intertemporal elasticity of substitution in consumption, $g^{c}$ is the growth rate of consumption per capita, and $\vartheta$ is the rate of time preference. This equation can be derived from the optimality conditions in Ikeda and Saito (2014), who constructed a dynamic general equilibrium model with demographic change. More specifically, by assuming a simple log utility function for both workers and nonworkers and assuming that workers' utility function does not depend on leisure, the optimality conditions could yield that: i) workers' consumption per capita is equal to nonworkers' consumption per capita, and ii) equation (27) holds with $g^{c}$ being the growth rate of consumption per capita and the intertemporal elasticity of substitution being 1 . Given that workers' consumption per capita is equal to non-workers' consumption per capita, we can generalize the intertemporal elasticity of substitution from 1 to $\sigma$. Therefore, following a similar way that Laubach and Williams (2003) generalize equation (27) to the equation that links the natural rate with the trend potential growth, we can assume that the natural rate, denoted by $r^{*}$, is a linear function of the trend growth rate of per capita potential output, $g^{\text {pot }}$, and other determinants, $z$ :

$$
r_{t}^{*}=c g_{t}^{p o t}+z_{t}
$$

Given that the trend growth rate of per capita potential output can be written as the difference between the trend growth rate of potential output and population growth rate, we can re-write equation (28) as

$$
r_{t}^{*}=c\left(g_{t}-\Delta n_{t}\right)+z_{t}
$$

where $g$ is the trend growth rate of potential output and $n$ is the logarithm of total population.

\section{Equation (29) implies that the impact of demographic change on the natural interest} rate depends on both the working-age population growth and the total population growth. In particular, if the negative impact of lower working-age population growth on the trend potential growth through equation (20) dominates the impact of lower total population growth, then the natural rate will decline. Moreover, equations (20) and (29) also imply that 
the natural rate of interest is increasing in the working-age population growth but decreasing in the total population growth, which is in line with the finding by Ikeda and Saito (2014). ${ }^{10}$

Following Pescatori and Turunen (2016) and IMF (2017), we assume that the process $Z$ (the other determinants of the natural rate) follows an autoregressive model with exogenous variables. Such exogenous variables include a measure of "excess" global savings $S_{t}$ (proxied by the current account surplus of emerging and developing economies expressed in terms of U.S. GDP), a measure of risk premium in Japan $E_{t}$ (proxied by two separate measures, namely, equity risk premium and bond market premium), and a newsbased measure of economic policy uncertainty in Japan $P_{t}:{ }^{11}$

$$
z_{t}=\delta_{1} z_{t-1}+\delta_{2} z_{t-2}-\delta_{s} \Delta S_{t}-\delta_{e} \Delta E_{t}-\delta_{p} \Delta P_{t}+\varepsilon_{t}^{Z}
$$

Compared to the original LW model, the exogenous observables included in the process $\boldsymbol{z}$ (or $\boldsymbol{z}$-determinants) help with identification. The original LW model specifies the process $z$ as a pure random walk without any observable determinant. Such a system may not provide sufficient information to back out, with a satisfactory degree of precision, the process $z$ (Pescatori and Turunen, 2016). The exogenous observables in equation (30) help mitigate this problem. Moreover, this specification is more in line with the global savings glut hypothesis where the exogenous variables of excess global savings and risk premium are also playing a role in driving the dynamics of the natural rate. In addition, according to Coeurdacier et al. (2015), higher global desired savings due to world population aging may also lower Japan's natural rate through the open capital account of Japan. Meanwhile, as discussed before, excess savings in Japan due to longevity and a rising old-age dependency ratio could also contribute to a lower natural rate in Japan. Therefore, to capture these effects as a robustness check, we also replace the measure of excess global savings with a measure of Japan's excess savings (i.e., the current account surplus of Japan) in equation (30). Equations (20)-(26) and (29)-(30) constitute a state-space model.

\section{Bayesian Estimation: Priors ANd Data}

The state-space model can be estimated with Bayesian methods. The Bayesian estimation method follows Pescatori and Turunen (2016). The posterior distributions combine prior information with the likelihood function calculated from our data sample. Using the Bayesian approach could have two main advantages compared to the standard maximum likelihood estimation (MLE) approach. First, as documented by Daníelsson et al. (2016), the likelihood function of the MLE is relatively flat in the case of Iceland as small changes in initial values

\footnotetext{
${ }^{10}$ Ikeda and Saito (2014) found that the growth rate of the share of working-age population in total population is the key demographic factor that affects the natural rate of interest. Since the share of working-age population in total population is monotonically decreasing in the old-age dependency ratio, our assumptions to some extent also capture the effects of the old-age dependency ratio on the trend growth of per capita potential output. This is likely to be the reason why adding the change in the old-age dependency ratio in equations (13)-(17) does not qualitatively change the estimation results.

${ }^{11}$ The equity and bond market premia will be discussed in detail in the next section.
} 
produced very different estimates. Second, the trend potential growth and the initial value of potential output are weakly identified in MLE (Pescatori and Turunen, 2016). By using Bayesian methods, the WEO output gap, even as an imprecise signal, helps impose some discipline to the estimates. The prior distributions and variables in the baseline model are specified as follows.

The Bayesian priors in the baseline model are generally set according to estimates from single-equation regressions and previous estimates available in the literature. We assume that all the common parameters in the system follow the same type of distribution as in Pescatori and Turunen (2016). The remaining two parameters, i.e., $\gamma_{0}$ and $\gamma_{1}$ (the coefficients of working-age population growth), are assumed to follow Gamma and Normal distributions, respectively, given that $\gamma_{0}$ is expected to be positive. ${ }^{12}$ The prior means and standard deviations of the parameters in the IS and Phillips curves are based on results from single-equation regressions of equations (22) and (23), respectively, except $\alpha_{r}$, where the single-equation estimate is very small and statistically insignificant. Moreover, as pointed out by Pescatori and Turunen (2016), $c$ is weakly identified in equation (29) as a higher value of $c$ is substantially offset by a lower initial value of $z_{t}$, leaving trend potential growth and output gap unaffected. Therefore, we use the estimated mean and standard error of $\alpha_{r}$ and $c$ by Fujiwara et al. (2016) as the prior mean and standard deviation, respectively.

\section{The priors of the remaining parameters are mainly based on Pescatori and Turunen}

(2016). For example, the priors on the parameters in the process $z_{t}$ (i.e., $\delta_{s}, \delta_{e}$, and $\delta_{p}$ ) are set relatively loose and defined on an unbounded support to allow the MCMC algorithm to explore wider intervals. Also, for the relation between the true output gap and the WEO output gap, we set loose priors for standard deviations $\sigma_{w}$ and $\sigma_{\mu}$, and a high prior mean of 0.95 for the persistence parameter $\rho$. The priors for all standard deviations are inverse gamma and distributed in line with Bayesian DSGE literature. The detailed prior distributions are presented in Table 1. With these assumptions of the prior distributions, we call the model our baseline model.

\footnotetext{
12 As a robustness check, we also estimate the model assuming that $\gamma_{0}$ follows a Normal rather than Gamma distribution. The estimation results are very similar.
} 


\begin{tabular}{|c|c|c|c|}
\hline \multicolumn{4}{|c|}{ Table 1. Priors } \\
\hline \multirow[b]{2}{*}{ Parameter } & \multicolumn{3}{|c|}{ Prior Distributions } \\
\hline & Density & Mean & SD \\
\hline$c$ & Gamma & 0.70 & 0.27 \\
\hline$\alpha_{1}$ & Gamma & 1.01 & 0.10 \\
\hline$\alpha_{1}+\alpha_{2}$ & Beta & 0.92 & 0.05 \\
\hline$\alpha_{r}$ & Gamma & 0.06 & 0.04 \\
\hline$\beta_{1}$ & Beta & 0.45 & 0.10 \\
\hline$\beta_{2}$ & Beta & 0.37 & 0.10 \\
\hline$\beta_{x}$ & Beta & 0.05 & 0.01 \\
\hline$\beta_{m}$ & dogmatic & 0.01 & \\
\hline$\delta_{1}$ & Gamma & 1 & 0.25 \\
\hline$\delta_{1}+\delta_{2}$ & Beta & 0.99 & 0.0025 \\
\hline$\gamma_{0}$ & Gamma & 0.014 & 0.01 \\
\hline$\gamma_{1}$ & Normal & 0.00 & 0.01 \\
\hline$\delta_{s}$ & Normal & 0.10 & 0.25 \\
\hline$\delta_{e}$ & Normal & 0.10 & 0.25 \\
\hline$\delta_{p}$ & Normal & 0.10 & 0.25 \\
\hline$\sigma\left(\varepsilon^{y}\right)$ & Inv. Gamma & 0.02 & Inf. \\
\hline$\sigma\left(\varepsilon^{x}\right)$ & Inv. Gamma & 0.97 & Inf. \\
\hline$\sigma\left(\varepsilon^{\pi}\right)$ & Inv. Gamma & 1.22 & Inf. \\
\hline$\lambda_{g}=\sigma\left(\varepsilon^{g}\right) / \sigma\left(\varepsilon^{y}\right)$ & Inv. Gamma & 0.45 & Inf. \\
\hline$\lambda_{z}=\sigma\left(\varepsilon^{z}\right) / \sigma\left(\varepsilon^{x}\right)$ & Inv. Gamma & 0.019 & Inf. \\
\hline$\sigma_{w}$ & Inv. Gamma & 0.50 & Inf. \\
\hline$\sigma_{\mu}$ & Inv. Gamma & 0.50 & Inf. \\
\hline$\rho$ & Beta & 0.95 & 0.01 \\
\hline \multicolumn{4}{|c|}{$\begin{array}{l}\text { Sources: Author's calculations; IMF (2017); and Pescatori and } \\
\text { Turunen (2016). }\end{array}$} \\
\hline
\end{tabular}

We use a quarterly sample from 1990Q1 to 2018Q1 on real GDP, core inflation, import relative price inflation, and the short-term real interest rate. Most of the data such as real GDP, potential output, output gap, and import inflation are obtained from the IMF's World Economic Outlook (WEO) database. Following Pescatori and Turunen (2016), the import relative price inflation is calculated by subtracting the core inflation from the import inflation. Core inflation (all items less fresh food and energy) is obtained from the Ministry of Internal Affairs and Communications. Short-term inflation expectations are calculated based on the inflation forecasts from Consensus Economics. ${ }^{13}$ The short-term real interest

\footnotetext{
${ }^{13}$ Consensus Economics collects inflation forecasts for the calendar year for Japan since October 1989.

Following Hogen and Okuma (2018), we take into account quarterly realizations of inflation within the forecast
} 
rate is calculated by subtracting the short-term inflation expectations from the uncollateralized overnight call rate. ${ }^{14}$ Data of total population and working-age population are obtained from the United Nations' World Population Prospects.

Measures for the $z$-determinants are broadly in line with Pescatori and Turunen (2016) and IMF (2017). Excess global savings are proxied by the current account surplus of emerging and developing economies (in percent of U.S. GDP). We use two separate measures of the risk premium, notably, the equity risk premium and bond market premium, following Pescatori and Turunen (2016) and IMF (2017), respectively. The equity risk premium is taken from the October 2018 Global Financial Stability Report (IMF, 2018), and the bond market premium is calculated simply as the spread between the Japanese and U.S. 10-year government bonds (denominated in local currencies) following IMF (2017). Finally, the economic policy uncertainty (EPU) index for Japan developed by Arbatli et al. (2017) is used as the news-based measure of economic policy uncertainty.

\section{Baseline Results}

The posterior distributions of the model parameters are sampled using a Monte Carlo Markov Chain (MCMC) algorithm, following Pescatori and Turunen (2016). Table 2 reports the mode, median, and percentile posterior estimates for the baseline model. ${ }^{15}$ The parameter estimates for the baseline model suggest that the natural rate of interest in Japan is indeed related to the trend potential growth, even though the parameter $c$ is not precisely estimated. The posterior mode for the coefficient of the contemporaneous working-age population growth, $\gamma_{0}$, is larger than the prior mean, while the posterior of the coefficient of the lagged working-age population growth, $\gamma_{1}$, is very close to a symmetric distribution. In addition, the sum $\delta_{1}+\delta_{2}$ is very close to 1 , suggesting that the $z$-process is highly persistent - similar to what Pescatori and Turunen (2016) found for the United States. Moreover, we also find that median estimates tend to assign more weight to the equity risk premium among the three observable determinants of $z$, even though the estimates are not statistically significant.

year and calculate short-term inflation expectations for the remaining quarters under the assumption that shortterm forecasts are equally paced in the remaining quarters.

${ }^{14}$ Since the short-term inflation expectations from the Consensus Economics are only available since 1990, we also estimate the model for a longer period (since 1980) using estimated inflation expectations before 1990 (estimated by a simple moving-average model of actual inflation) as a robustness check. The estimated natural rate of interest and the demographic impact after 1990 are qualitatively similar to the baseline estimates presented in the next section.

${ }^{15}$ Convergence of the Markov chain is achieved in all the estimations in this paper. 


\begin{tabular}{|c|c|c|c|c|c|c|c|c|}
\hline \multirow[b]{3}{*}{ Parameter } & \multicolumn{4}{|c|}{ Posterior } & \multicolumn{4}{|c|}{ Posterior } \\
\hline & \multicolumn{4}{|c|}{ Equity risk premium } & \multicolumn{4}{|c|}{ Bond market premium } \\
\hline & Mode & Median & $10^{\text {th }}$ & $90^{\text {th }}$ & Mode & Median & $10^{\text {th }}$ & $90^{\text {th }}$ \\
\hline$c$ & 0.566 & 0.643 & 0.372 & 1.021 & 0.563 & 0.647 & 0.373 & 1.031 \\
\hline$\alpha_{1}$ & 1.045 & 1.034 & 0.945 & 1.126 & 1.045 & 1.034 & 0.944 & 1.124 \\
\hline$\alpha_{1}+\alpha_{2}$ & 0.927 & 0.909 & 0.856 & 0.951 & 0.927 & 0.908 & 0.857 & 0.952 \\
\hline$\alpha_{r}$ & 0.016 & 0.027 & 0.009 & 0.062 & 0.019 & 0.030 & 0.011 & 0.066 \\
\hline$\beta_{1}$ & 0.430 & 0.424 & 0.342 & 0.508 & 0.430 & 0.426 & 0.344 & 0.509 \\
\hline$\beta_{2}$ & 0.388 & 0.389 & 0.287 & 0.491 & 0.388 & 0.386 & 0.287 & 0.489 \\
\hline$\beta_{x}$ & 0.047 & 0.051 & 0.039 & 0.065 & 0.047 & 0.051 & 0.039 & 0.064 \\
\hline$\delta_{1}$ & 0.919 & 0.962 & 0.685 & 1.305 & 0.927 & 0.953 & 0.685 & 1.290 \\
\hline$\delta_{1}+\delta_{2}$ & 0.991 & 0.990 & 0.986 & 0.993 & 0.991 & 0.990 & 0.987 & 0.993 \\
\hline$\gamma_{0}$ & 0.023 & 0.012 & 0.004 & 0.027 & 0.023 & 0.012 & 0.004 & 0.027 \\
\hline$\gamma_{1}$ & 0.009 & 0.000 & -0.013 & 0.013 & 0.009 & 0.000 & -0.013 & 0.013 \\
\hline$\delta_{s}$ & 0.221 & 0.210 & -0.118 & 0.526 & 0.217 & 0.191 & -0.120 & 0.514 \\
\hline$\delta_{e}$ & 0.156 & 0.106 & -0.204 & 0.437 & 0.236 & 0.235 & -0.079 & 0.555 \\
\hline$\delta_{p}$ & 0.225 & 0.206 & -0.115 & 0.532 & 0.220 & 0.188 & -0.136 & 0.515 \\
\hline$\sigma\left(\varepsilon^{y}\right)$ & 0.009 & 0.014 & 0.007 & 0.031 & 0.009 & 0.014 & 0.008 & 0.043 \\
\hline$\sigma\left(\varepsilon^{x}\right)$ & 0.951 & 0.944 & 0.866 & 1.036 & 0.950 & 0.945 & 0.867 & 1.033 \\
\hline$\sigma\left(\varepsilon^{\pi}\right)$ & 0.900 & 0.904 & 0.831 & 0.989 & 0.900 & 0.904 & 0.832 & 0.988 \\
\hline$\lambda_{g}=\sigma\left(\varepsilon^{g}\right) / \sigma\left(\varepsilon^{y}\right)$ & 0.221 & 8.485 & 5.764 & 13.090 & 0.221 & 10.492 & 7.693 & 16.979 \\
\hline$\lambda_{z}=\sigma\left(\varepsilon^{z}\right) / \sigma\left(\varepsilon^{x}\right)$ & 0.009 & 0.012 & 0.007 & 0.025 & 0.009 & 0.012 & 0.007 & 0.024 \\
\hline$\sigma_{w}$ & 0.365 & 0.293 & 0.261 & 0.332 & 0.365 & 0.291 & 0.260 & 0.329 \\
\hline$\sigma_{\mu}$ & 0.281 & 0.276 & 0.248 & 0.307 & 0.281 & 0.273 & 0.247 & 0.305 \\
\hline$\rho$ & 0.972 & 0.963 & 0.950 & 0.973 & 0.972 & 0.962 & 0.949 & 0.973 \\
\hline
\end{tabular}

The baseline estimates show a declining trend in the natural rate of interest in Japan since the 1990s (Figure 1). We estimate the baseline model using two measures of risk premium, namely, the equity risk premium and the bond market premium. The results of the two estimations are very similar, except that the estimates using the equity risk premium show a stronger decline in the aftermath of the GFC - similar to the estimates of the United States by Pescatori and Turunen (2016) using the U.S. equity risk premium. Although the range of estimates is relatively large, suggesting that the natural rate is estimated imprecisely, the Bayesian medians from both estimations suggest that Japan's natural rate in Q1 2018 was likely to be negative, but close to zero. Moreover, the median estimates also suggest that the natural rate in Japan has likely fallen into negative territory since the Asian Financial Crisis 
(AFC). ${ }^{16}$ It is also worth noticing that, similar to the finding by Pescatori and Turunen (2016), the range of estimates also widens during and in the aftermath of the GFC, suggesting more significant uncertainty about the natural rate during that period.

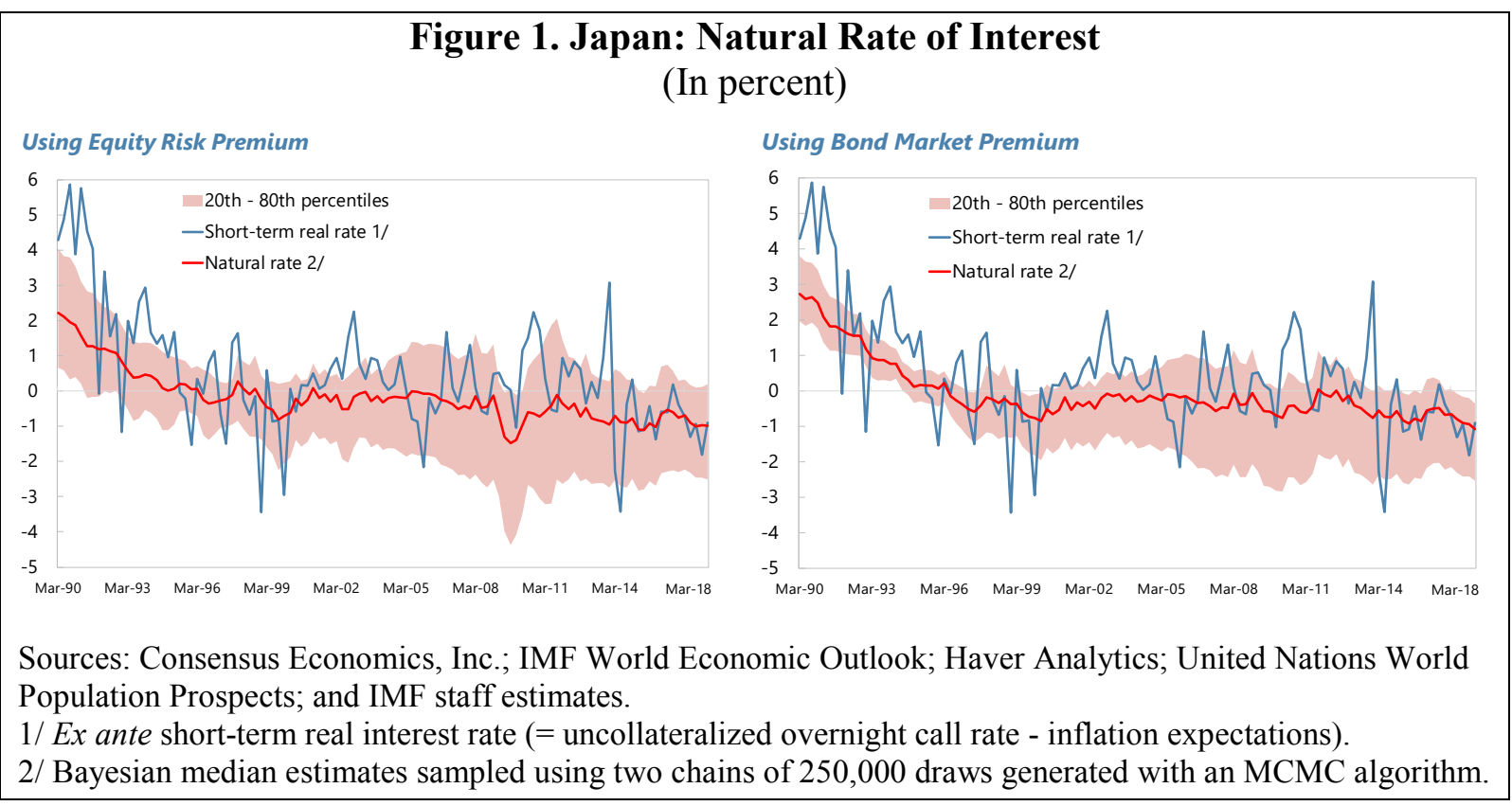

The baseline results also suggest that the quantitative and qualitative monetary easing (QQE) by the BoJ since April 2013 has successfully pushed down the real interest rate, although it has been difficult to widen the interest rate gap. Broadly speaking, the shortterm real interest rate has been on a declining trend since 2013 (Figure 1). ${ }^{17}$ Although the short-term real interest rate has been below the median estimates of the natural rate since 2017, suggesting a negative interest rate gap and an accommodative monetary policy stance, the interest rate gap has been relatively small (less than one percentage point) and has shrunk significantly in Q1 2018. This is because, on the one hand, the natural rate has been on a declining trend since 2016, and on the other hand, it is still very difficult to have a steady increase in inflation expectations. This implies that the monetary stimulus provided to the economy seems to be relatively limited and may have even diminished more recently. It is important to note that while the interest rate gap is a useful summary indicator of the monetary policy stance, it is an incomplete, and-given the uncertainties associated with estimation of the natural rate-imprecise measure (Pescatori and Turunen, 2016). Some other

\footnotetext{
${ }^{16}$ Fujiwara et al. (2016) also found that the natural rate of interest in Japan fell below zero during and in the aftermath of the AFC. However, the median estimates in our model are more persistent and have not returned to positive territory since then.

17 The sharp increase and subsequent decrease in the short-term real interest rate during late 2014 was mainly due to the change in inflation expectations caused by the consumption tax hike (from 5 percent to 8 percent) in October 2014. We also estimate the model using inflation expectations without the effects of consumption tax hikes, and the estimates of the natural rate are very similar to the baseline estimates.
} 
indicators of financial conditions (such as bank lending), which are not entirely captured by the interest rate gap, could also affect the policy stance.

The baseline estimates confirm that demographic change has had a significantly negative impact on the natural rate of interest in Japan, and more importantly, this impact has increased in recent years. Figure 2 presents the historical decomposition of the median estimates of the natural rate from the baseline estimation using the equity risk premium, as well as the decomposition of the $z$-determinant. ${ }^{18}$ Clearly, demographic changes have been putting a downward pressure on the natural rate in Japan. ${ }^{19}$ More importantly, the negative impact increased steadily since around 2005 when the working-age population growth started to decline faster than total population growth. This is in line with the finding by Ikeda and Saito (2014) that a decline in the share of working-age population in total population lowers the real interest rate and the natural rate in Japan.

The negative demographic impact has stabilized in recent years as the working-age population growth recovered slightly, but is expected to increase significantly after the early 2020s. Figure 2 shows that the negative impact of demographic change on the natural rate has stabilized at around -0.5 percent in recent years. This is primarily due to the slight recovery in working-age population growth, which increased the share of the working-age population in total population. These estimates of the demographic impact have similar magnitudes as those based on a DSGE model with demographic factors and financial frictions by Okazaki and Sudo (2018). ${ }^{20}$ Going forward, given that working-age population growth is projected by the United Nations to decline much faster than the total population growth after early 2020s, the negative impact of demographics on the natural rate in Japan could resume an increasing trend.

Other shocks to trend potential growth (such as technology shocks) have played a more important role in driving the natural rate in Japan. Our results show that trend potential growth (excluding the contribution from demographics) is indeed an important driver of the natural rate in Japan (Figure 2). Trend potential growth was relatively high in early 1990s, which contributed to a high natural rate back then in Japan. However, it had declined significantly in the 1990s, pushing down the natural rate in Japan into negative territory. While there was some recovery during the pre-GFC period and after the GFC, the

\footnotetext{
${ }^{18}$ The $z$-determinant includes excess global savings (proxied by the current account balance of emerging market and developing countries), as well as equity risk premium and economic policy uncertainty in Japan. The decompositions based on the baseline estimates using the bond market premium are very similar to those using the equity risk premium, and hence are suppressed here.

${ }^{19}$ One caveat of this result is that the relatively short time period in the estimation may lead to a smaller estimated impact of demographic change than the actual impact, particularly at the beginning of the sample, due to the non-stationary nature of demographic impact. In other words, the demographic impact in the current period also depends on the impact in previous periods.

${ }^{20}$ However, the baseline estimate of Japan's natural rate by Okazaki and Sudo (2018) is about 1 percent as of Q2 2017, which is much higher than our baseline estimate and also higher than the natural rate estimates for the United States and Euro area by Holston et al. (2017).
} 
contribution from trend potential growth to the natural rate has stabilized at low levels (only about one third of its level in 1990) in recent years. These findings highlight the need to boost the trend potential growth to offset the negative and increasing impact of demographics on the natural rate, and thereby lift the natural rate and widen the interest rate gap. This could include, for example, accelerating labor market reforms and other structural reforms (Colacelli and Fernandez-Corugedo, 2018).

Figure 2. Japan: Determinants of the Natural Rate of Interest 1/
(In percent)
Decomposition of the Natural Rate
3.0 Other factors (z-determinant) $3 /$
2.5
2.0
1.5
0.0
0.0

Other factors in the $z$-determinant, particularly the risk premium, have also contributed to the lower natural rate in Japan since the AFC. The equity risk premium in Japan estimated by the Global Financial Stability Report (IMF, 2018) rebounded rapidly to historical highs after the GFC, putting a substantial downward pressure on the natural rate of interest (Figure 2). Similarly, Pescatori and Turunen (2016) also found that equity risk premium had a significantly negative impact on the natural rate in the United States after the GFC. This is because that all the major advanced economies experienced a rapid increase in their equity risk premia after the GFC. However, the U.S. equity risk premium has since declined to levels that are only slightly higher than historical levels, while the equity risk premium in Japan remains relatively high compared to historical levels. As a result, the negative impact of equity risk premium on the natural rate has diminished significantly in the United States but not in Japan. ${ }^{21}$

\footnotetext{
${ }^{21}$ According to the estimates by IMF (2018), the equity risk premium in Japan has not declined significantly amid the BoJ's ETF purchases since the introduction of QQE in April 2013.
} 
Moreover, we also find some supporting evidence for the global savings glut hypothesis. As emerging market economies started to accumulate foreign exchange reserves after the AFC, the resulting excess global savings and higher demand for safer assets (such as U.S. and Japanese assets) put significant downward pressure on the natural rate in Japan (Figure 2). This is particularly the case during the period between AFC and GFC. Moreover, this is also in line with the finding by Pescatori and Turunen (2016) that the decline in the U.S. natural rate in the early 2000 s reflects a significant increase in demand for U.S. assets due to substantial increases in emerging market current account surpluses during this period. ${ }^{22}$ These findings together provide some evidence for the global savings glut hypothesis during the period between AFC and GFC. However, after the GFC, the negative impact of excess global savings on the natural rate in Japan has diminished and even reversed in recent years - similar to what Pescatori and Turunen (2016) found for the United States.

The results should be interpreted with caution. First, the estimates only capture the impact of demographic changes on the natural rate through the trend potential growth channel, while other channels that could affect savings (such as lower fertility, longevity, and the changing preference over safe assets amid population aging) are not captured. Second, the estimates have relatively large error bands. As a result, the inferences based on the median estimates could be imprecise and subject to high uncertainty.

\section{ROBUSTNESS}

The baseline results are qualitatively robust to changes in the Bayesian priors. Due to the aforementioned weak identification issue of $c$ and the very small estimate of $\alpha_{r}$ from a single-equation regression, we also use different priors of these parameters obtained from alternative sources other than Fujiwara et al. (2016). Based on Pescatori and Turunen (2016) and Holston et al. (2017), who estimated the parameters for the natural rate in the United States, we estimate our model with their means and standard deviations of the prior distributions of these parameters (Table 3). The estimates are presented in Figure 3. It is worth noticing

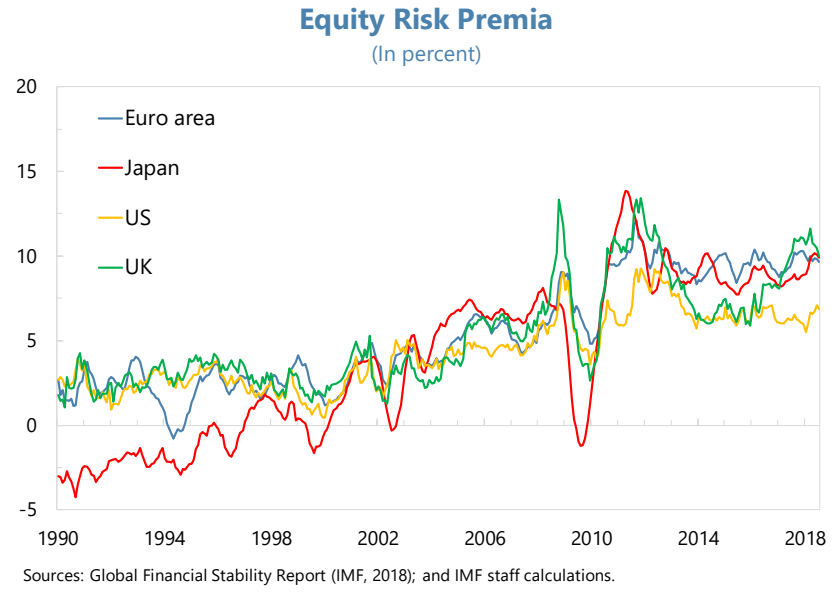
that the median estimates of the natural rate in Japan are slightly higher than the baseline estimates, leading to larger interest rate gaps than in the baseline. However, the negative impact of demographics on the natural rate has also been rising in recent years, and explained

\footnotetext{
${ }^{22}$ The "safety" status of Japanese assets similar to the U.S. assets is in line with Caballero et al. (2017).
} 
about half of the negative natural rate in Q1 2018 (around -0.8 percent). These results are very similar to the baseline estimates.

\section{Figure 3. Japan: Natural Rate of Interest with Alternative Priors 1/ (In percent)}

\section{Using alternative priors of $c$ and $\alpha_{r}$ from Pescatori and Turunen (2016)}
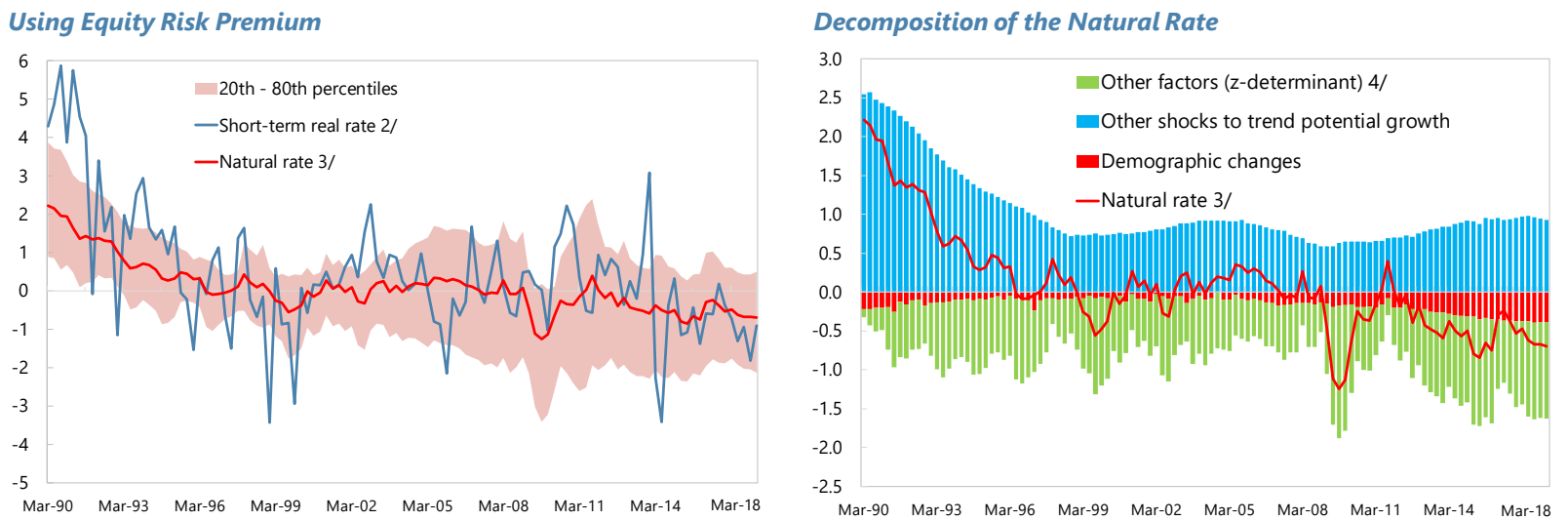

\section{Using alternative priors of $c$ and $\alpha_{r}$ from Holston et al. (2017)}
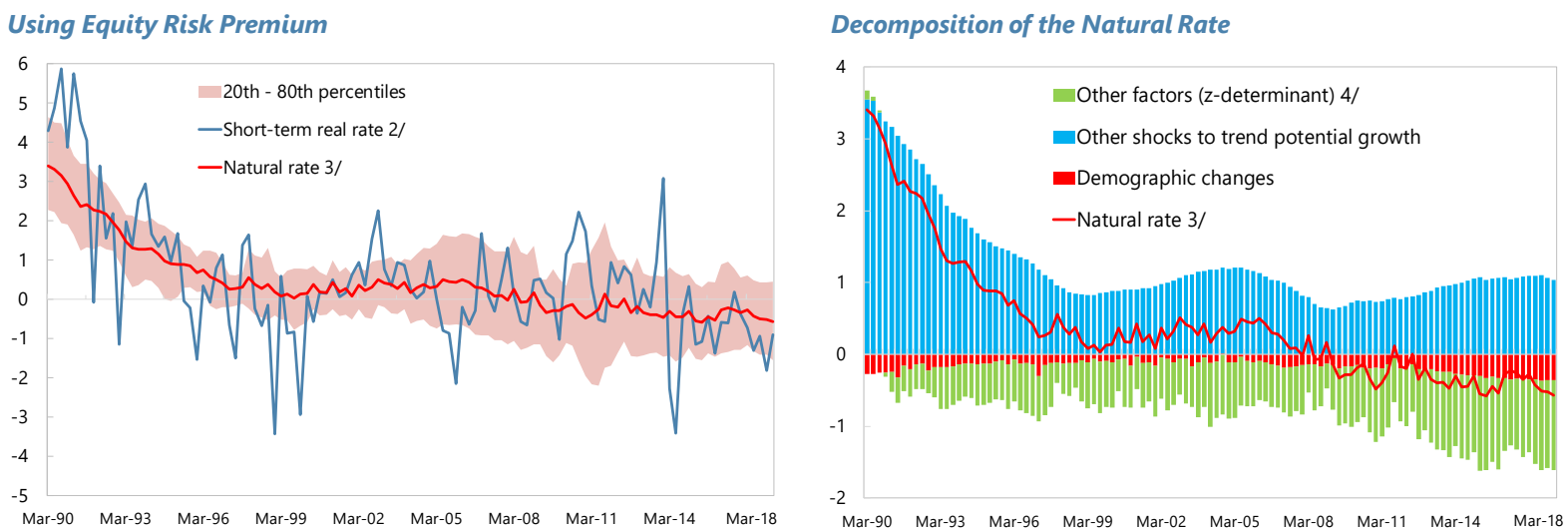

Sources: Consensus Economics, Inc.; IMF World Economic Outlook; Haver Analytics; United Nations World Population Prospects; and IMF staff estimates.

1 / We only present the estimates using the equity risk premium here, as the estimates using the bond market premium are similar.

2/ Ex ante short-term real interest rate (= uncollateralized overnight call rate - inflation expectations).

3/ Bayesian median estimates sampled using two chains of 250,000 draws generated with an MCMC algorithm.

4/ The $z$-determinant includes excess global savings, as well as equity risk premium and economic policy

uncertainty in Japan.

To capture - to some extent - the other channels of demographic effects, we also estimate the model with a measure of Japan's excess savings rather than the measure of global excess savings. As discussed before, the impact of other demographic factors such as longevity and old-age dependency ratio typically operates through increasing the desired savings in the economy. Therefore, we use a measure of Japan's excess savings, i.e., the 
current account surplus in percent of GDP, to replace the measure of global excess savings in equation (30). The estimates are presented in Figure 4. The estimated demographic impact on the natural rate of interest (denoted by the red bars) is comparable with the baseline impact. In addition to the impact of equity risk premium and policy uncertainty, the $z$-determinant in panels 2 and 3 of Figure 4 also captures, to some extent, the impact of the other demographic factors discussed above on the natural rate. Unlike the global excess savings, Japan's excess savings had a negative impact on domestic natural rate in recent years. This is consistent with the increasing longevity and old-age dependency ratio in Japan.

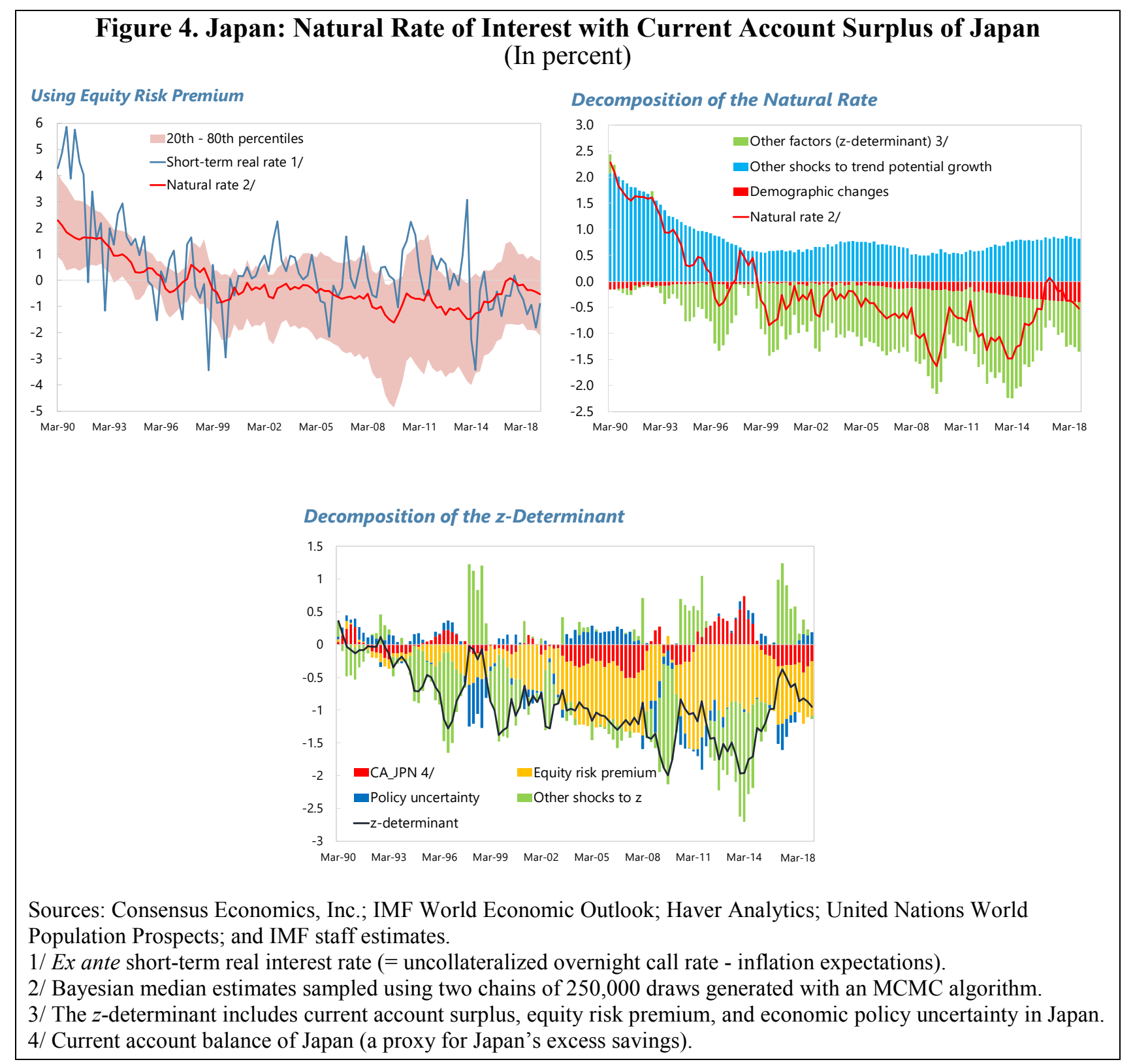


We also estimate the model without the exogenous variables in the $z$-process (or $z$ controls). To better understand the role of the $z$-determinant in driving the natural rate, we follow Laubach and Williams (2003) and replace equation (30) with the assumption that $Z$ follows a simple random walk:

$$
z_{t}=z_{t-1}+\varepsilon_{t}^{Z}
$$

\begin{tabular}{|lllll|}
\hline \multicolumn{4}{c}{ Table 3. Alternative Priors of $\boldsymbol{c}$ and $\boldsymbol{\alpha} \boldsymbol{r}$} \\
\hline Parameter & Density & Mean & SD & Source \\
\hline$c$ & Gamma & 0.81 & 0.05 & Pescatori and Turunen (2016) \\
$\alpha_{r}$ & Gamma & 0.08 & 0.05 & Pescatori and Turunen (2016) \\
$c$ & Gamma & 1 & 0.05 & Holston et al. (2017) \\
$\alpha_{r}$ & Gamma & 0.07 & 0.02 & Holston et al. (2017) \\
\hline
\end{tabular}

The estimation results without the $z$-controls are similar to the baseline estimates, albeit with a higher persistence. Figure 5 presents the estimates of the model assuming $z$ follows the simple random-walk process in equation (31). The median estimates of the natural rate are slightly higher but similar to the baseline estimates. However, the median estimates seem to be more persistent than the baseline estimates. This is likely because that the $z$-controls introduced in equation (30) capture more short-term movements, while the random-walk process in equation (31) are more persistent and less affected by short-term movements. Moreover, the contribution from demographic changes to the natural rate accounts for a larger share among the contributions from all determinants of the natural rate. The median estimates also indicate a larger interest rate gap than the baseline estimates, suggesting higher monetary stimulus compared to the baseline results, however, such an interest rate gap is also closing more recently. 


\section{Figure 5. Japan: Natural Rate of Interest without $z$-Controls}

(In percent)
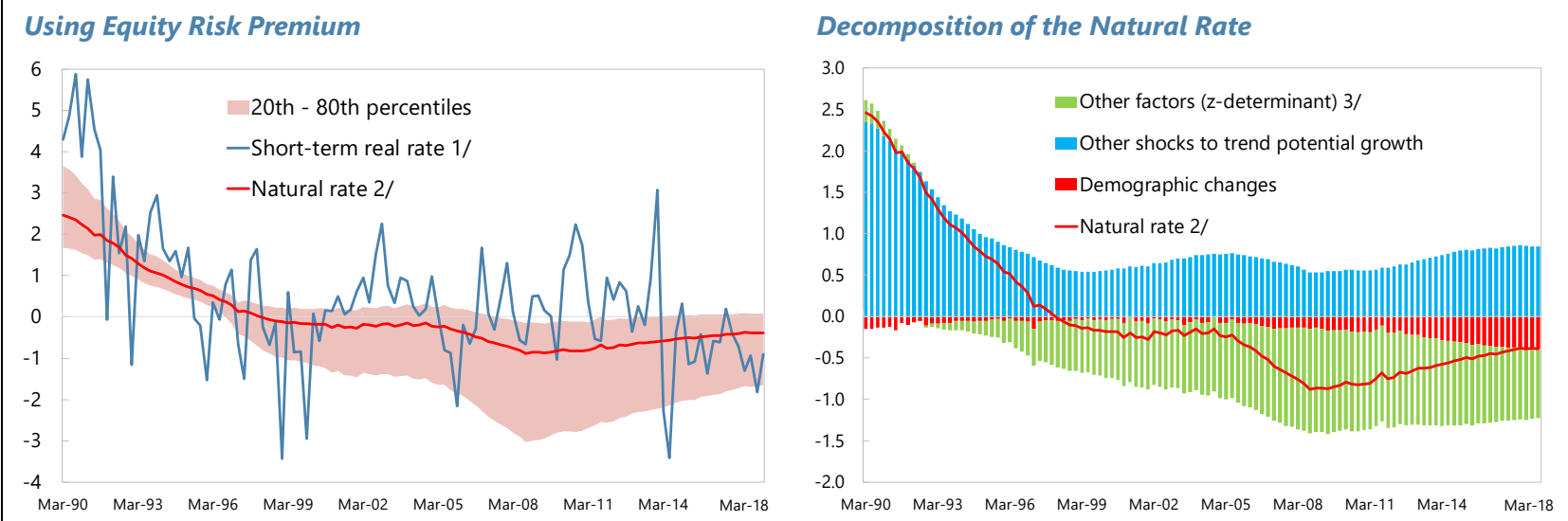

Sources: Consensus Economics, Inc.; IMF World Economic Outlook; Haver Analytics; United Nations World Population Prospects; and IMF staff estimates.

1/ Ex ante short-term real interest rate (= uncollateralized overnight call rate - inflation expectations).

2/ Bayesian median estimates sampled using two chains of 250,000 draws generated with an MCMC algorithm.

3/ The $z$-determinant here follows a simple random walk.

We also replace the short-term interest rate with the 10 -year interest rate, as the effects of QQE may not be captured by the short-term interest rate. More specifically, we replace the short-term real interest rates, $r_{t-1}$ and $r_{t-1}$, in equation (22) with the 10-year real interest rate, calculated by subtracting inflation expectations from the 10-year Japanese Government Bond (JGB) yield. The estimation results are presented in Figure 6. There are several similarities between these estimates and the baseline results. First, the median estimates of the natural rate (based on the 10-year interest rate) have been on a declining trend since the 1990s and have fallen into negative territory in recent years. Moreover, the interest rate gap is also relatively limited and closing more recently.

However, some differences between the estimates using the 10-year interest rate and the baseline estimates are worth noting. First, the median estimates based on the 10-year interest rate have only fallen below zero since around 2012, while the baseline estimates based on the short-term interest rate have been negative since the AFC. More importantly, the size of the (negative) contribution of demographic change to the natural rate based on the 10 -year interest rate is similar to the size of the contribution in the baseline. Other shocks to the trend potential growth also had similar (positive) contributions to the 10-year-based natural rate compared to the baseline. However, the $z$-determinant has a much smaller (negative) contribution to the 10-year-based natural rate than to the baseline natural rate. This suggests that the $z$-determinants (which are less structural than the demographic change or other shocks to the trend potential growth) may be relatively less important in driving the 10year-based natural rate than driving the short-term-based natural rate. In other words, the more structural shocks including demographic change may play a relatively more important role in driving the 10-year-based natural rate. In the context where the BoJ is putting more emphasis on the 10-year interest rate target through its Yield Curve Control policy, 
demographic change could be relatively more important in terms of affecting the monetary policy stance. In this context, it is important to boost trend potential growth to offset the negative and increasing impact from demographics, thereby lifting the natural rate and widening the interest rate gap.

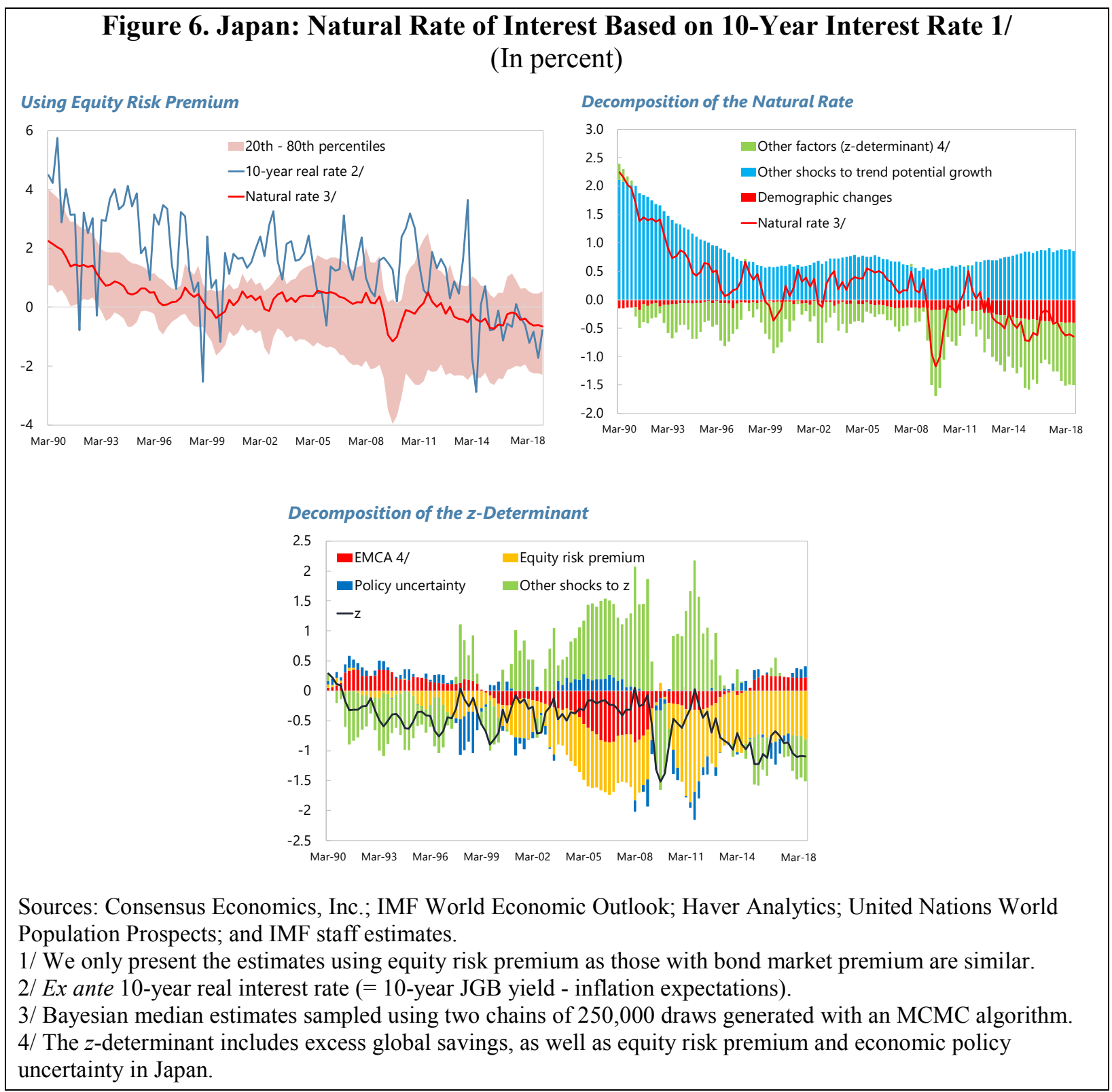

VI. Conclusions And Policy Implications

We use a semi-structural model to estimate the impact of demographic change on the natural rate of interest in Japan. Our empirical framework is based on the seminal work of Laubach and Williams (2003) and Pescatori and Turunen (2016). By using the production function approach, the framework explicitly models the impact of demographic changes on 
the natural rate of interest through the potential growth channel. Moreover, we follow Pescatori and Turunen (2016) and use a Bayesian approach to estimate the model, which incorporates prior information on the output gap and includes other exogenous observables (such as excess global savings and risk premia) as potential determinants of the natural rate.

Our results show that demographic change has contributed to the decline in Japan's natural rate, with this contribution increasing over time. This finding lends support to the secular stagnation hypothesis which posits that fundamental factors, particularly demographics in Japan's context, contributed to the decline in the natural rate by reducing the labor force and slowing productivity growth - thereby lowering trend potential growth. Moreover, the results show that the negative impact of demographic change, particularly declining working-age population, on the natural rate in Japan has been increasing in recent years. In addition, other shocks to trend potential growth (such as technology and other productivity shocks) also play an important role in driving the natural rate. We also find some evidence for the global savings glut hypothesis, particularly during the early 2000s, when excess global savings and equity risk premium contributed negatively to the natural rate. Although the results should be interpreted with caution for the reasons mentioned above, they are qualitatively robust to different priors and interest rate variables.

The results also suggest that Japan's natural rate has likely fallen into negative territory, highlighting the need to move forward with structural reforms to boost potential growth and lift the natural rate. The Bayesian median estimates suggest that the natural rate in Japan has likely fallen below zero since the AFC. In this context, with the working-age population growth projected to decline further by 2040, the negative demographic impact on the natural rate in Japan is likely to increase, which may further limit the role of monetary policy in reflating the economy. These findings highlight the importance of boosting potential growth by, for example, accelerating labor market and other structural reforms (including more active migration policies) to offset the increasing adverse demographic impact and raise the natural rate in Japan. 


\section{REFERENCES}

Aiyar, S., Ebeke, C., and X. Shao, 2016, "The Impact of Workforce Aging on European Productivity," IMF Working Paper No. 16/238, Washington D.C.: International Monetary Fund.

Arbatli, E. C., Davis, S. J., Ito, A., Miake, N., and I. Saito, 2017, "Policy Uncertainty in Japan," IMF Working Paper No. 17/128, Washington D.C.: International Monetary Fund.

Barsky, R., Justiniano, A., and L. Melosi, 2014, "The Natural Rate of Interest and Its Usefulness for Monetary Policy," American Economic Review, Vol. 104, No. 5, pp. 37-43.

Bernanke, B. S., 2005, "The Global Savings Glut and the U.S. Current Account Deficit," Sandridge Lecture, Virginia Association of Economists, Richmond.

Bernanke, B. S., 2017, “Some Reflections on Japanese Monetary Policy,” Brookings Institute.

Caballero, R. J., Farhi, E., and P. O. Gourinchas, 2017, “The Safe Assets Shortage Conundrum,” Journal of Economic Perspectives, Vol. 31, No. 3, pp. 29-46.

Carvalho, C., Ferrero, A., and F. Nechio, 2016, "Demographics and Real Interest Rates: Inspecting the Mechanism," Working Paper 2016-05, Federal Reserve Bank of San Francisco.

Colacelli, M., and E. Fernandez-Corugedo, 2018, “Macroeconomic Effects of Japan's Demographics: Can Structural Reforms Reverse Them?” IMF Working Paper No. 18/248, Washington D.C.: International Monetary Fund.

Coeurdacier, N., Guibaud, S., and K. Jin, 2015, "Credit Constraints and Growth in a Global Economy," American Economic Review, Vol. 105, No. 9, pp. 2828-2881.

Curdia, V., Ferrero, A., Ng, G. C., and A. Tambalotti, 2015, "Has U.S. Monetary Policy Tracked the Efficient Interest Rate?” Journal of Monetary Economics, Vol. 70, pp. 72-83.

Daníelsson, Á., Helgason, Ó. S., and S., Thórarinsson, 2016, "Estimating the Natural Interest Rate for Iceland: An Exploratory Study,” Working Paper No. 74, Central Bank of Iceland.

Feyrer, J., 2007, “Demographics and Productivity," The Review of Economics and Statistics, Vol. 89, Issue 1, pp. 100-109.

Fries, S., Mesonnier, J., Mouabbi, S., and J. Renne, 2016, "National Natural Rates of Interest and the Single Monetary Policy in the Euro Area", Banque de France, Working Paper No. 611.

Fujiwara, S., Iwasaki, Y., Muto, I., Nishizaki, K., and N. Sudo, 2016, "Development in the Natural Rate of Interest in Japan," Supplementary Paper Series for the "Comprehensive Assessment" (2), Bank of Japan Review, 2016-E-12. 
Hakkio, C. S., and A. L. Smith, 2017, "Bond Premiums and the Natural Real Rate of Interest," Federal Reserve Bank of Kansas City, KCFED Economic Review, First Quarter, pp. 5-38.

Hogen, Y., and R. Okuma, 2018, "The Anchoring of Inflation Expectations in Japan: A Learning-Approach Perspective," Bank of Japan Working Paper Series No. 18-E-8.

Holston, K., Laubach, T., and J. C. Williams, 2017, "Measuring the Natural Rate of Interest: International Trends and Determinants," Journal of International Economics, Vol. 108, pp. 59-75.

Ikeda D., and M. Saito, 2014, "The Effects of Demographic Changes on the Real Interest Rate in Japan," Japan and the World Economy, Vol. 32, pp. 37-48.

Imakubo, K., Kojima, H., and J. Nakajima, 2015, “The Natural Yield Curve: Its Concept and Measurement," Bank of Japan Working Paper Series No. 15-E-5.

International Monetary Fund (IMF), 2017, G-20 Report on Strong, Sustainable, and Balanced Growth, IMF Annual Meetings, October, Washington D.C.: International Monetary Fund.

International Monetary Fund, 2018, Global Financial Stability Report, October, Washington D.C.: International Monetary Fund.

Kawamoto, T., Ozaki, T., Kato, N., and K. Maehashi, 2017, "Methodology for Estimating Output Gap and Potential Growth Rate: An Update," BoJ Reports \& Research Papers, Research and Statistics Department, Bank of Japan.

Laubach, T., and J. C. Williams, 2003, "Measuring the Natural Rate of Interest," Review of Economics and Statistics, Vol. 85, pp. 1063-1070.

Lewis, K. F., and F. Vazquez-Grande, 2017, "Measuring the Natural Rate of Interest: Alternative Specifications," Board of Governors of the Federal Reserve System, Finance and Economics Discussion Series No. 2017-059.

Liu, Y., and N. Westelius, 2017, "The Impact of Demographics on Productivity and Inflation in Japan," Journal of International Commerce, Economics and Policy, Vol. 8, No. 2.

Lubik, T. A., and C. Matthes, 2015, "Calculating the Natural Rate of Interest: A Comparison of Two Alternative Approaches," Economic Brief, Federal Reserve Bank of Richmond, No. $15-10$.

Okazaki, Y., and N. Sudo, 2018, "Natural Rate of Interest in Japan -Measuring its Size and Identifying Drivers Based on a DSGE Model," Bank of Japan Working Paper Series No. 18E-6. 
Pescatori, A., and J. Turunen, 2016, "Lower for Longer: Neutral Rate in the U.S.," IMF Economic Review, Vol. 64, pp. 708-731.

Sudo, N., and Y. Takizuka, 2018, "Population Aging and the Real Interest Rate in the Last and Next 50 Years -A Tale Told by an Overlapping Generations Model," Bank of Japan Working Paper Series No. 18-E-1.

Summers, L. H., 2014, "U.S. Economic Prospects: Secular Stagnation, Hysteresis, and the Zero Lower Bound,” Business Economics, Vol. 49, No. 2, pp. 65-73. 